\title{
WIRES
}

RNA

WILEY

\section{Pat1 RNA-binding proteins: Multitasking shuttling proteins}

\begin{tabular}{|c|c|}
\hline Journal: & WIRES RNA \\
\hline Manuscript ID & RNA-883.R1 \\
\hline Wiley - Manuscript type: & Advanced Review \\
\hline $\begin{array}{l}\text { Date Submitted by the } \\
\text { Author: }\end{array}$ & $\mathrm{n} / \mathrm{a}$ \\
\hline Complete List of Authors: & $\begin{array}{l}\text { Vindry, Caroline; Centre International de Recherche en Infectiologie } \\
\text { Weil, Dominique; Institut de Biologie Paris-Seine } \\
\text { Standart, Nancy; University of Cambridge }\end{array}$ \\
\hline Keywords: & $\begin{array}{l}\text { RNA processing, 5'-3' decay, 3'-5' decay, deadenylation, alternative } \\
\text { splicing }\end{array}$ \\
\hline $\begin{array}{l}\text { Choose } 1-3 \text { topics to } \\
\text { categorize your article: }\end{array}$ & $\begin{array}{l}\text { Regulation of RNA Stability (RHAC) }<\text { RNA Turnover and Surveillance } \\
\text { (RHAA), Splicing Regulation/Alternative Splicing (RFAD) }<\text { RNA } \\
\text { Processing (RFAA), Translation Regulation (REAF) }<\text { Translation (REAA) }\end{array}$ \\
\hline
\end{tabular}

\section{SCHOLARONE $^{\text {m }}$ Manuscripts}




\title{
Pat1 RNA-binding proteins: Multitasking shuttling proteins
}

\author{
Caroline Vindry ${ }^{1}$, Dominique Weil ${ }^{2}$ and Nancy Standart ${ }^{3}$ \\ ${ }^{1}$ Centre International de Recherche en Infectiologie, CIRI, 69007 Lyon, France \\ ${ }^{2}$ Sorbonne Université, CNRS, Institut de Biologie Paris-Seine, Laboratoire de Biologie du \\ Développement, F-75005 Paris, France. \\ ${ }^{3}$ Department of Biochemistry, University of Cambridge, Cambridge, UK
}

\begin{abstract}
Post-transcriptional regulation of gene expression is largely achieved at the level of splicing in the nucleus, and translation and mRNA decay in the cytosol. While the regulation may be global, through the direct inhibition of central factors, such as the spliceosome, translation initiation factors and mRNA decay enzymes, in many instances transcripts bearing specific sequences or particular features are regulated by RNA-binding factors which mobilize or impede recruitment of these machineries. This review focuses on the Pat1 family of RNAbinding proteins, conserved from yeast to man, that enhance the removal of the $5^{\prime}$ cap by the decapping enzyme Dcp1/2, leading to mRNA decay and also have roles in translational repression. Like Dcp1/2, other decapping co-activators including DDX6 and Edc3, and translational repressor proteins, Pat1 proteins are enriched in cytoplasmic P-bodies, which have a principal role in mRNA storage. They also concentrate in nuclear Cajal-bodies and splicing speckles and in man, impact splice site choice in some pre-mRNAs. Pivotal to these functions is the association of Pat1 proteins with distinct heptameric Lsm complexes: the cytosolic Pat1/Lsm1-7 complex mediates mRNA decay and the nuclear Pat1/Lsm2-8 complex alternative splicing. This dual role of human Pat1b illustrates the power of paralogous complexes to impact distinct processes in separate compartments. The review highlights our recent findings that Pat1b mediates the decay of AU-rich mRNAs, which are particularly enriched in P-bodies, unlike the decapping activator DDX6, which acts on GCrich mRNAs, that tend to be excluded from P-bodies, and discuss the implications for mRNA decay pathways.
\end{abstract}




\section{Caption}

The conserved family of Pat1 nucleocytoplasmic shuttling RNA-binding proteins mediate a wide range of RNA processing steps including AU-rich mRNA decay, translational repression and alternative splicing, depending on its associated heptameric Lsm complexes, and are found enriched in membrane-less RNP granules including cytoplasmic P-bodies and nuclear Cajal bodies.

\section{Introduction}

The Pat1 family of RNA-binding proteins (RBPs) mediate mRNA decay in the cytoplasm, a role that is shared by homologues from primitive land plants to man. Its founder member is the $S$. cerevisiae homolog, Pat1p, identified though a two hybrid interaction as a protein associated with topoisomerase II (Wang et al. 1996). Red alga, fungi, flies and worms have one Pat1 paralog while vertebrates possess two (see Fig.1 for names), which are differentially expressed. Pat1a/PATL2 proteins in Xenopus, mice and man are present in oocytes but decayed during oocyte maturation, and are replaced by newly synthesised Pat1b/PATL1 in eggs which are further expressed in embryos and the soma (Fig.1 (Marnef et al. 2010; Marnef and Standart 2010; Nakamura et al. 2010; Chen et al. 2017; ChristouKent et al. 2018). The functional importance of this protein family is demonstrated by genetic studies. Deletion of S. cerevisae Pat1p results in a slow growth phenotype at $30^{\circ} \mathrm{C}$ and lethality at $37^{\circ} \mathrm{C}$ (Wang et al. 1996; Bouveret et al. 2000). S. pombe Pdc2 mutants are defective in recovery from glucose starvation (Wang et al. 2017) and deletion of $D$. melanogaster or C. elegans Pat1 proteins is embryonic lethal (Kamath et al. 2003; Pradhan et al. 2012). Pat1b homozygous null mice are sub-viable, meaning incomplete penetrance of preweaning lethality; only 1 such pup survived compared to 32 WT pups (IMPC, http://www.mousephenotype.org). In the case of Pat1a/PATL2, bi-allelic missense and nonsense mutations lead to infertility. Four recent studies report that women carrying PATL2 mutations and Pat|2-/-mice exhibit oocyte maturation defects, an extremely rare primary cause of female infertility (Chen et al. 2017; Maddirevula et al. 2017; Christou-Kent et al. 2018; Huang et al. 2018).

Pat1 proteins do not contain any obvious feature or motif known to mediate protein or RNA interactions. Their N-terminal regions are predicted to be largely disordered, are proline-rich and tend not conserved amongst paralogs. In contrast, the so-called Mid and 
PatC domains are highly conserved and predicted to be largely a-helical, though only the structure of PatC has been solved (Fig.2 ). PatC forms a so called a-a superhelix, an elongated domain related to the ARM repeat and HEAT repeat family of proteins (Braun et al. 2010; Sharif and Conti 2013; Wu et al. 2014). At steady state Pat1 proteins are found principally in the cytoplasm, where they are enriched in P-bodies, membrane-less compartments that store untranslated mRNAs and contain RNA-binding proteins including translational repressors and decay machinery (Luo et al. 2018; Standart and Weil 2018). Moreover, fungal and human Pat1b proteins shuttle to nuclei, in a Crm1-dependent manner, with an estimated $15 \%$ being nuclear in proliferating HEK293 cells (Teixeira and Parker 2007; Marnef et al. 2012; Vindry et al. 2017; Wang et al. 2017). The binding partners of Pat1 proteins include mRNA decay enzymes and co-activators (CCR4/NOT, Dcp1/2, Xrn1, Lsm1-7, Edc3, Edc4; see Box 1 for an overview of mRNA decay pathways), translational repressor proteins (DDX6, 4E-T), additional RNA-binding proteins (Lsm14A) and snRNP components (U4/5/6 snRNP). Our recent transcriptome analysis of the effects of Pat1b depletion in human cells revealed the up-regulation of a large class of mRNAs and specific splicing alterations in some transcripts. In addition to universal roles in mRNA decay and a role in alternative splicing in man, Pat1 proteins repress translation in yeast and in Xenopus oocytes. In this review we will discuss our current understanding of Pat1 protein function in mRNA decay, splicing and translational repression, in the light of their interactome and how they bind to RNA, and end on consideration of their evolutionary conservation. We will highlight our recent findings indicating that Pat1b mediates the decay of AU-rich mRNAs, which are particularly enriched in P-bodies, unlike the decapping activator DDX6, which facilitates the decay of GC-rich mRNAs, that tend to be excluded from P-bodies, and discuss the implications of these observation for mRNA decay pathways.

\section{Box 1}

\section{Overview of cytoplasmic mRNA decay pathways}

The half-lifes of eukaryotic mRNAs vary considerably between transcripts, dictated by multiple parallel and partially redundant decay pathways in collaboration with cis-acting RNA elements and trans-acting RNA-binding proteins. Decay is typically initiated by deadenylation of the $3^{\prime}$ poly $(A)$ tail, catalyzed by PAN2/PAN3 and the large multiple subunit CCR4-NOT deadenylase enzymes, and in the major decay pathway, deadenylation leads to 
decapping by DCP1/DCP2, a step which allows the highly processive 5'-3' exonuclease Xrn1 access to the $5^{\prime}$ end of the transcript, resulting in 5'-3' decay. Several conserved activators of the decapping enzyme have been identified including Edc3, Edc4, Dhh1/DDX6, the Lsm17 heptamer and Pat1 proteins. Alternatively, deadenylation enables the exosome nuclease complex access to the body of the mRNA at the $3^{\prime}$ end, leading to $3^{\prime}-5^{\prime}$ decay (reviewed (Łabno et al. 2016; Grudzien-Nogalska and Kiledjian 2017)). Recent studies have shown that the initial trigger for mRNA decay may not always be deadenylation, but may be due to 3' extension of the transcript by several uridine residues by terminal uridyltransferases (TUTases). Of note, uridylation and deadenylation can proceed both sequentially and in parallel, and uridylation-dependent decapping is enhanced by the Lsm1-7 complex. Following decapping, Xrn1 degrades these transcripts 5' $-3^{\prime}$ while the Dis312 nuclease and the exosome degrade oligo-uridylated transcripts 3'-5' (reviewed (Scott and Norbury 2013; De Almeida et al. 2018)).

\section{Identifying proteins that interact with Pat1}

In light of the multiple roles of this RBP family, examination of the proteins that bind Pat1 proteins was a key issue. Yeast two hybrid approaches (Fromont-Racine et al. 2000) (Pilkington and Parker 2008; Alhusaini and Coller 2016)), co-immunoprecipitation studies including BiolD (Youn et al. 2018) coupled with western blotting (Bouveret et al. 2000; Tharun et al. 2000; Braun et al. 2010; Haas et al. 2010; Nissan et al. 2010; Ozgur et al. 2010), and mass spectrometry (Vindry et al. 2017) have identified conserved Pat1 mRNA decay/translational repression co-factors from fungi and metazoa and revealed novel association with splicing factors in human cells. Except where noted otherwise, all the interactions reported below are RNA-independent. Table 1.

Arguably the best characterized amongst these co-factors are the Like-sm (Lsm) proteins, structurally similar to the Sm family of proteins, which form heteroheptameric rings and bind RNA. Sm and Lsm protein families are present in all three domains of life and mediate RNA annealing, unwinding, decay and stabilization. In eukaryotes Lsm proteins are best known for roles in mRNA turnover and splicing, via Lsm1-7 and Lsm2-8 respectively. While Sm proteins bind U1, U2, U4 and U5 snRNAs and function in splicing, the nuclear Lsm2-8 complex interacts with U6 snRNA. In contrast, the cytoplasmic Lsm1-7 complex has been characterized as a decapping activator, and mediates mRNA decay (reviewed (Beggs 
2005; Tharun 2009)). The interaction between yeast Lsm1-7 and Pat1 has been captured in a crystal where the PatC domain binds a composite surface of Lsm2 and Lsm3 with a rather rigid recognition mechanism between folded domains (Sharif and Conti 2013). The PatC region is missing or mutated in many PATL2 infertility patients due to premature termination codons or missense mutations, as summarized in (Huang et al. 2018), illustrating its importance for Pat1 protein function.

Also a key conserved partner of Pat1 proteins is the translational repressor/decapping co-activator DEAD box RNA helicase DDX6. Human DDX6 interacts with translational repressors and with the decapping enzyme Dcp1/2 and its activators (Ayache et al. 2015), and its depletion results in both translational activation and mRNA stabilization of distinct transcripts (Courel et al. 2018). In yeast its homologue Dhh1 has been characterized as a decapping co-activator as well as a translational repressor (reviewed in (Presnyak and Coller 2013). In this case, the structure has been determined between a $\mathrm{N}$ terminal yeast Pat1 peptide and the second RecA domain of Dhh1/DDX6 (Sharif et al. 2013). This DDX6 domain also binds the decapping co-activator Edc3, the RNA-binding protein Lsm14A and the elF4E-binding protein 4E-T, in a mutually exclusive manner (Tritschler et al. 2009; Ozgur et al. 2015; Brandmann et al. 2018). Interestingly, the N-terminal Pat1 peptide and DDX6 binding is conserved between yeast, flies and human Pat1b, though not human Pat1a proteins (Braun et al. 2010; Haas et al. 2010; Ozgur et al. 2010; Vindry et al. 2017). Nevertheless, the DDX6-binding peptide is present in Xenopus Pat1a, as well as in XPat1b, and indeed both interact with Xp54/DDX6 (Marnef et al. 2010; Nakamura et al. 2010; Ayache et al. 2015), and this is likely the case for zebrafish too, based on sequence alignments.

The decapping enzyme Dcp1/2 as well as Edc3 and Edc4 (found only in metazoa) decapping enhancers and the Xrn1 5'-3' exonuclease all interact with Pat1 proteins. $S$. cerevisiae Pat1p harbours an extended C-terminal domain compared to its human counterpart, and it is this extension that binds Dcp2, at multiple sites, as well as Xrn1, very likely in a mutually exclusive manner (He and Jacobson 2015; Charenton et al. 2017). It is less clear where the decapping enzyme binds human Pat1b, and whether it does so directly, as in yeast. It appears that Dcp2 co-precipitates with both the $\mathrm{N}$-terminal and the C-terminal halves of Pat1b, whereas Dcp1a preferentially associates with the proline-rich domain (Ozgur et al. 2010), though another study finds Dcp2 binding only to PatC (Braun et al. 
2010). It is important to note that the decapping enzyme composition and architecture differs between yeast and metazoa (reviewed (Charenton and Graille 2018)), as only the yeast Dcp2 protein contains the multiple HLM (short leucine-rich helical motifs) that bind Pat1 (He and Jacobson 2015; Charenton et al. 2017), and the interaction between human Dcp1 and Dcp2, and between Dcp1 and Xrn1 is bridged and enhanced by the metazoan specific Edc4 (Chang et al. 2014).

In addition to the $5^{\prime}-3^{\prime}$ decay factors, human Pat $1 \mathrm{~b}$ also interacts with the multisubunit Ccr4/Not deadenylase complex (Ozgur et al. 2010; Vindry et al. 2017; Youn et al. 2018). With the BiolD approach, able to detect transient association, the entire complex bound Pat1b (Youn et al. 2018). Binding was noted for the N-terminal half or Mid domain of Pat1b and HPat respectively (Haas et al. 2010; Ozgur et al. 2010). In yeast, only the two related Not3/5 subunits, lacking catalytic (Not6/7) or bridging (Not1) ability have been reported to bind Pat1p (Alhusaini and Coller 2016).

The RNA-binding proteins Lsm14A/B, or Scd6 in yeast, interact with Pat1, but details of this binding and its role remain to be studied (Nissan et al. 2010; Brandmann et al. 2018). The metazoan translational repressor 4E-T, which binds the cap-binding protein elF4E precluding it from interacting productively with elF4G to initiate translation, also coprecipitates with human Pat1b (Nishimura et al. 2015; Kamenska et al. 2016; Youn et al. 2018) and Xenopus Pat1a (Minshall et al. 2007; Nakamura et al. 2010). This interaction is independent of DDX6, a well-characterized 4E-T co-factor, as 4E-T has separate binding sites for Pat1b and DDX6 (Ozgur et al. 2015; Kamenska et al. 2016). And last in this compilation of the cytoplasmic interactors of Pat1 proteins are the miRISC components Drosophila Ago1 and GW182, and human Ago1/2 and TNRC6 proteins (Barišić-Jäger et al. 2013; Nishihara et al. 2013; Youn et al. 2018), suggesting a possible role in miRNA silencing.

As to its nuclear co-factors, we recently showed that human Pat1b interacts with components of the U4, U5, U6 tri-snRNP (see Box 2 for role of tri-snRNP in splicing). In particular, the Mid +PatC domains of Pat1b co-immunoprecipitate SART3 (Prp24 in yeast) in an RNA-dependent manner, and Lsm2-8, Prp3, Prp4, Prp31 and other components in the absence of RNA. Pat1b also interacts with $U 4$ and U6 snRNAs, but not U1 snRNA, and altogether sets up the Pat1b/Lsm2-8/U6 snRNA/SART3 axis (Vindry et al. 2017). A proteomic analysis of column-based fractionations of nuclear and cytoplasmic proteins of HeLa and HEK293 cells identified several hundred soluble complexes (Havugimana et al. 2012). 
Interestingly, one of the largest complexes includes Pat1b and tri-snRNP components (eg Prp3, Prp4, Prp6, Prp8, Prp31) and additional splicing proteins. While SART3 was not found in this complex, this may reflect the nuclease treatment used to prepare the cell lysate (Havugimana et al. 2012). More recently, the BiolD approach identified several tri-snRNP components such as Prp3 and Prp4 co-purifying with human Pat1b (Youn et al. 2018). And last, as yeast Pat1p was detected in U6-containing penta-snRNP (Stevens et al. 2002), we anticipate these interactions to be conserved.

\section{Box 2}

\section{Overview of the role of tri-snRNP in splicing}

Splicing of pre-mRNA is catalyzed by the spliceosome. This dynamic machinery is composed of several small nuclear ribonucleoprotein particles (U1, U2, and U4/U6.U5 snRNPs) and non-snRNP factors. During a splicing cycle, U1 and U2 snRNP recognize 5' and 3' splice sites respectively; then the binding of U4/U6.U5 tri-snRNP trigger spliceosome rearrangement and remodeling into a catalytically active spliceosome. During this process, U1 and U4 snRNPs are released and additional factors join the spliceosome. At the end, the spliceosome disassembles before the next round of splicing. Thus, U4, U5 and U6 snRNPs enter the splicing cycle as a 1.5 MDa pre-assembled complex. The assembly of the tri-snRNP involves base pairing between U4 and U6 snRNA and addition of specific proteins such as Lsm proteins and SART3. The U5 snRNA is then attached by protein-protein binding (for example Prp31 and Prp6). After a splicing cycle, new tri-snRNP assembly occurs in part in Cajal Bodies.

\section{Cellular distribution of Pat1 proteins: residence in RNP granules}

As introduced earlier, Pat1 proteins shuttle between cytoplasm and nuclei, and are found enriched in RNP granules in both compartments. Fig.3.

It has been appreciated for some time that Pat1 proteins localize to cytoplasmic P(rocessing)-bodies in yeast (Sheth and Parker 2003; Pilkington and Parker 2008), Drosophila (Haas et al. 2010) and human cells (Braun et al. 2010; Marnef et al. 2010; Ozgur et al. 2010). P-bodies are non-membranous organelles, constitutively present in mammalian cell lines, averaging $0.5 \mu \mathrm{m}$ in diameter, with 10 or less per cell (reviewed in (Luo et al. 2018; Standart and Weil 2018)). Until recently, P-bodies were thought of mainly as centers of 
mRNA degradation in part due to their concentration of decay factors, as detailed below, though a few examples of stored mRNAs that can return to translation have been documented (Standart and Weil 2018). However, recent novel particle sorting and imaging approaches revealed that purified P-bodies harbor intact untranslated mRNAs, and that mRNAs, including ARE mRNAs (bearing AU-rich elements), are not decayed in P-bodies (Horvathova et al. 2017; Hubstenberger et al. 2017). RNP granules such as P-bodies form by liquid-liquid phase transition in which viscous droplets condense in the liquid cytosol. These transitions are mediated by several types of molecular interactions including specific, high affinity protein-protein binding, low affinity binding between low-complexity protein domains or intrinsically disordered regions (IDR) and interactions between RNA and proteins, which provide an additional platform for multivalent protein binding (Ditlev et al. 2018; Luo et al. 2018; Standart and Weil 2018). Numerous interactions and RNA assemblies based on combinations of specific interactions and promiscuous IDRs are common features of RNP granules including P-bodies in eukaryotic cells (Jonas and Izaurralde 2013; Protter et al. 2018).

Interestingly, even after overexpression, only Pat1b, but not Pat1a localizes to Pbodies in mammalian cell lines (Marnef et al. 2010). DDX6 was a good candidate to mediate this localization, since it is highly enriched in P-bodies and binds Pat1b but not Pat1a. However, the P-rich, Mid and PatC domains of Pat1b were implicated in this targeting, rather than the N-terminal DDX6-binding region (Braun et al. 2010; Ozgur et al. 2015).

Strikingly, proteins related to RNA metabolism comprise at least $75 \%$ of human PB content (Hubstenberger et al. 2017). Prior immunostaining and fluorescent protein-tagging approaches as well as the more recent analysis of purified P-bodies generally agree that they fall into the categories of mRNA decay, translational control and RNA interference: 5'3' decay (Dcp1/2, Xrn1), decapping activators (Edc3, Edc4, Pat1b, Lsm1-7), deadenylase factors (Ccr4/Not, Pan3), RNAi/miRNA silencing factors (Ago1-4, GW182), nonsense mediated decay factors (Upf1, Smg5, Smg7), translational repression factors (the helicase DDX6, the elF4E-binding protein 4E-T and the RNA-binding proteins (Lsm14A, CPEB1, IGF2BP1/3 and PUM1/2) (reviewed in (Ditlev et al. 2018; Luo et al. 2018; Standart and Weil 2018); (Hubstenberger et al. 2017)). While the 5'-3' decay pathway is well represented, components of the 3'-5' exosome have not been identified in P-bodies. Interestingly, however, TUT4 uridylase is enriched in P-bodies (Hubstenberger et al. 2017). 
As this list closely resembles that of the Pat1b interactome, the link strongly suggested that Pat1b acts as a scaffolding P-body protein or that it associates with such proteins. Several studies addressed this question in depleted or genetically deleted cells. In S. cerevisae, S. pombe and human cells lines, lowered or absent levels of Pat1 proteins only partially reduced P-body size and/or number, showing that they are not absolutely required for P-body assembly (Teixeira and Parker 2007; Marnef et al. 2010; Ayache et al. 2015; Wang et al. 2017), and are thus not critical scaffolds. In man these have been defined as DDX6, 4E-T and Lsm14A, which all bind each other (Ayache et al. 2015; Kamenska et al. 2016; Brandmann et al. 2018), illustrating both the redundancy of assembly factors and their multivalent interactions. Yet, phosphorylation of yeast Pat1 by Protein kinase A inhibits P-body formation (Ramachandran et al. 2011; Sachdev et al. 2019), while phosphomimetic mutation of the equivalent potential PKA site in human GFP-Pat1b rendered it dominant negative for endogenous P-bodies (Vindry et al. 2017). Thus, Pat1b clearly has a contributory role in P-body assembly whose molecular mechanism has yet to be elucidated. A potential clue arises from recent In vitro experiments suggesting that yeast Pat1p enhances the phase separation of Dhh1 (DDX6) and RNA into liquid droplets (Sachdev et al. 2019).

Pat1b's nuclear life in granules was revealed following the identification of its NES (Nuclear Export Signal), whose mutagenesis prevented export, thus enabling visualization of its enrichment in PML, splicing speckles (Marnef et al. 2012) and Cajal bodies (Vindry et al. 2017). The function of Pat $1 b$ in these granules is best understood in the case of Cajal bodies, involved in aspects of short non-coding RNA metabolism, including tri-snRNP assembly (reviewed in (Staněk 2016)), as discussed further below.

Pat1b is by no means a unique P-body shuttling protein, but it is the only so far with clearly defined and distinct roles in the cytoplasm and nucleus. Other such proteins include 4E-T (Dostie et al. 2000; Kamenska et al. 2014), DDX6 (Huang et al. 2017) as well as Lsm14B and Lsm1/4 (Kırlı et al. 2015). Intriguingly, this shuttling group partly overlaps that of the essential P-body assembly factors. 4E-T, Lsm14B and Lsm1/4, as well as Pat1b, rely on Crm1, the mediator protein for the leucine-rich NES-dependent export pathway, while DDX6 is cotransported with one of its partners, such as 4E-T, Lsm14B and/or possibly Pat1b in a piggyback manner (Kırlı et al. 2015; Huang et al. 2017). It is not known if and how Pat1b 
nucleocytoplasmic shuttling is regulated, though it is notable that the nuclear form of Pat1b is modified, likely by phosphorylation (Vindry et al. 2017).

\section{How Pat1 proteins bind RNA}

Pat1 proteins bind RNA both when complexed with Lsm proteins, and in an Lsmindependent manner. Pat1-Lsm1-7 form a stable stoichiometric complex that has been purified from yeast and extensively characterized by Tharun and colleagues. The complex preferentially binds oligoadenylated rather than polyadenylated mRNA, facilitated by a stretch of U-residues near the $3^{\prime}$ end of reporter RNAs, with $3^{\prime} A_{5}$ being dominant over the presence of a U-tract. And yet, in vitro, in gel-shift assays, the complex only interacts with oligo(U) and no other oligomer (Chowdhury et al. 2007). Interestingly, a stretch of Uresidues forms the binding site of the Lsm2-8 complex, which binds the 3' end of U6 snRNA. Recent CLIP analysis confirms the preferential though not exclusive binding of yeast Pat1 and Lsm1 to $3^{\prime}$ ends of mRNAs, with a single binding site for Pat1 identified in most mRNAs (Mitchell et al. 2013). The absence of a strong consensus binding sequence suggests that the proteins of the complex may simply recognize the $3^{\prime}$ oligo(A) and the proximal U-rich stretch.

However, separately, the Lsm1-7 ring is severely impaired in RNA-binding, and indeed both Pat1 and Lsm1-7 contribute to the RNA-binding activity of the complex (Chowdhury et al. 2014), though quite how they collaborate to do so isn't yet understood. It is also not clear, in the absence of any Pat1/Lsm1-7/RNA co-crystal, whether the mRNA 3' end threads through the central cavity of the Lsm1-7 ring. In the case of yeast Lsm2-8, whose structure with U6 snRNA has been solved (Zhou et al. 2014; Montemayor et al. 2018), the 3' end of U6 snRNA, which terminates in 5 U-residues, binds the ring's interior and proximal face. In yeast Lsm1-7, the C-terminal extension of Lsm1 partially occupies the internal channel of the ring (Sharif and Conti 2013), and it may be that Pat1 binding to the Lsm1-7 ring alleviates this potential obstruction to the RNA exit site. This would rationalize the need for both Pat1 and Lsm1-7 for optimal RNA affinity, as well as the observation that the C-terminal extension of Lsm1 is important for the RNA-binding activity of the complex (Chowdhury et al. 2012).

Secondly, Pat1 can also bind RNA directly. In the purified yeast complex, both Pat1 and Lsm1 UV-crosslink to reporter RNA (Chowdhury et al. 2014). More recently, 
interactome capture, which detects proteins with the capacity to crosslink to poly $\left(\mathrm{A}^{+}\right) \mathrm{RNA}$ on a genome-wide scale, showed that yeast and human Pat1 proteins bind RNA (Baltz et al. 2012; Castello et al. 2012; Beckmann et al. 2015). A new interactome approach based on organic phase separation and independent of crosslinking verified this finding (Queiroz et al. 2019).

While studies of full-length Pat1 proteins have been hampered by their insolubility in E. coli, analysis of fragments has been informative. The recombinant human PatC domain (Fig. 2) co-elutes with synthetic poly(U) in gel filtration assays, which further demonstrated its preference for $U_{30}$ over $U_{15 / 20}$, and over $A_{30}$ (Braun et al. 2010). A conserved patch composed of arginines and lysines at the $\mathrm{N}$-terminus of PatC has been proposed to mediate RNA interactions (Braun et al. 2010; Wu et al. 2014), and indeed mutagenesis of six of these basic residues in the human domain abrogated co-elution with $U_{30}$ (Braun et al. 2010). This basic patch in PatC may extend the surface of interaction with RNA by the Lsm1-7 ring in the complex, explaining its preferred interaction with longer RNAs.

The M (Mid) domain of Pat1 proteins (Fig. 2) has also been shown to interact with RNA. Pat1 proteins synthesized in vitro in the rabbit reticulocyte lysate are retained on poly(U) Sepharose beads, though it cannot be excluded that they do so associated with Lsm proteins of the lysate. Both $\mathrm{M}$ and PatC regions in yeast Pat1 independently promote this poly(U)-binding activity (Pilkington and Parker 2008; Marnef et al. 2010). In an extension of the interactome approach, RBDmap was recently developed to determine the RNA-binding sites of native RBPs on a proteome-wide scale (reviewed (Hentze et al. 2018)). This approach involves UV-crosslinking, subsequent capture of mRNP with oligo(dT), their proteolytic digestion, a second oligo(dT) purification and ultimately the mass spectrometry analysis of RNA-bound peptides and those released initially. In HeLa and cardiomyocytic HL1 cells, crosslinks were identified in two neighbouring peptides in the Pat1 Mid domain, as well as a peptide corresponding to the basic patch in PatC (Liao et al. 2016; Castello et al. 2017). The Mid domain thus binds RNA directly and may also participate in stable interaction with the PatC domain and the Lsm1-7 complex (Braun et al. 2010; Lobel et al. 2019).

Altogether, both Pat1 proteins and the Lsm1-7 ring collaborate to interact with RNAs, with a preference for those ending in oligo(A), nearby a stretch of uridine residues. 


\section{Identifying the role of Pat1 proteins in mRNA decay}

Early studies in yeast showed that deletion of Pat1p led to the stabilization of deadenylated/ oligoadenylated but capped mRNAs, leading to its functional definition as an enhancer of decapping (Bonnerot et al. 2000; Bouveret et al. 2000; Tharun et al. 2000). These observations also suggested that Pat1 bound mRNAs undergoing deadenylation, in line with its RNA-binding preference. Two reporter mRNAs were typically used in these studies, the unstable MFA2 and stable PGK mRNAs, engineered with a 3'UTR polyG-tract to trap decay intermediates as it effectively blocks exonucleases (Decker and Parker 1993). Pat1p deletion reduced the level of the $5^{\prime}$ truncated intermediate leading to the accumulation of intact mRNA and increased its half-life approx. 4 fold (Bonnerot et al. 2000; Bouveret et al. 2000; Tharun et al. 2000). Moreover, Pat1p enhances the enzymatic activity of Dcp2 in vitro (Nissan et al. 2010). Similar observations in deletion strains were made for Lsm1-7, though not Lsm8 (Boeck et al. 1998; Bouveret et al. 2000; Tharun et al. 2000), indicating that Pat1p acts in concert with Lsm1-7. Indeed, the interaction between Pat1 and Lsm1-7 (mediated by Lsm2 and 3) is required for optimal rates of decay of MFA2pG mRNA in vivo (Wu et al. 2014). The decapping role of Pat1p is conserved in S. pombe as deadenylated mRNA was also stabilized in fission yeast Pdc2 mutant strains (Wang et al. 2017).

Most studies of metazoan Pat1 proteins addressing their role in mRNA decay were performed with the tether function approach, whereby a tagged version of the protein of interest is tethered to the 3'UTR of a reporter mRNA via phage hairpin motifs that are recognized by the tag peptide. These experiments showed that Pat1 reduced the level of bound luciferase mRNA, with minimal effects on their translation in mammalian and fruitfly cells (Haas et al. 2010; Ozgur et al. 2010; Totaro et al. 2011; Kamenska et al. 2014). Moreover, tethered Pat1b/HPat both deadenylates and decaps bound mRNAs in cells (Haas et al. 2010; Ozgur et al. 2010; Totaro et al. 2011). However, HPat is not required for deadenylation activity per se as its depletion leads to the accumulation of deadenylated reporter mRNA (Haas et al. 2010). Thus the apparent additional deadenylation activity of tethered metazoan Pat1 proteins may reflect their ability to stably recruit CCR4/NOT factors. Interestingly, tethered Pat1a, not expressed in mammalian tissue culture cells, was inert in such assays (Ozgur et al. 2010), pointing to a fundamental difference between the paralogs. Taking a different approach, Braun et al. 2010 showed that Pat1b 
immunoprecipitated from HEK293 cells was active in decapping assays in vitro, presumably due to its interactions with Dcp2.

Altogether, evidence from a variety of approaches, including deletion, depletion and tether function assays accompanied by use of dominant negative mutants of decapping and deadenylase enzymes indicates that Pat1 proteins act as decapping enhancers in fungi, fruitflies and man, and its involvement in deadenylation in metazoa is supported by tether function assays and the presence of the CCR4/NOT complex it its interactome.

In our recent studies of the transcriptome following Pat1b silencing in HEK293 cells, which stabilized $60 \%$ of significantly changed mRNAs (Vindry et al. 2017), we found no evidence for the decay of the most up-regulated mRNAs from the $5^{\prime}$ end (Courel et al. 2018). Indeed, genome-wide rather than reporter mRNA evidence in yeast too suggests that following decapping a significant fraction of the transcripts up-regulated in cells lacking Pat1p or Lsm1 is efficiently decayed 3'-5', rather than by the 5'-3' Xrn1 exonuclease, leading to a considerable revision of the decay mechanism for these transcripts (He et al. 2018). The 3'-5' decay may be mediated by the exosome or by Dis 3 L2 as this nuclease recognizes 3' uridine tracts bound by Lsm1-7 and other decapping components in S. pombe and human cells (Song and Kiledjian 2007; Malecki et al. 2013; Łabno et al. 2016). In the case of S. cerevisae which lack terminal uridyltransferases, $3^{\prime}-5^{\prime}$ decay will result presumably just from exosome activity.

To summarize, we propose that Pat1 proteins together with Lsm1-7 recognize and bind mRNAs 3 ' ends in the process of deadenylation, and those that terminate in uridine residues, and recruit Dcp1/2 to remove 5' caps. Then, we speculate that these uncapped mRNAs may be subsequently principally decayed from the $3^{\prime}$ rather than from the $5^{\prime}$ end by the exosome and/or Dis3L2. This model is built on the considerable binding and decapping data and the more recent, albeit incomplete, evidence of Pat1-mediated 3'-5' decay in yeast and man.

\section{mRNA targets of Pat1 proteins}

Recent studies have provided insights into the mRNA targets of Pat1 proteins. The CLIP approach revealed that yeast Pat1 binds at the very 3 ' ends of mRNAs. Secondly, as expected, there was a substantial overlap between Pat1- and Lsm1-bound mRNAs, and this overlap extended to Dhh1 targets (Mitchell et al. 2013). In agreement, the transcriptomic 
analysis of yeast deletion strains, showed a considerable overlap between up-regulated, stabilized, mRNAs in $\Delta$ Pat1 and $\Delta$ Lsm1 cells. However, unexpectedly, the overlap between $\Delta$ Pat1 or $\Delta$ Lsm1 and $\Delta$ Dhh1 up-regulated mRNAs was considerably less, indicating that Pat1/Lsm1 and Dhh1 largely target specific sub-sets of mRNAs. Interestingly, too, almost as many mRNAs were down-regulated in levels as up-regulated in these three strains, suggesting indirect deletion effects (He et al. 2018). Some particular transcripts, not normally bound, were found to interact with the Pat1/Lsm1-7 complex In budding yeast cells subject to osmotic stress or nitrogen depletion, to effect their translational repression or stabilization (Garre et al. 2018; Gatica et al. 2019).

Depletion of Pat1b from HEK293 cells also resulted in a substantial down-regulation of mRNAs (40\%) as well as the up-regulation (60\%) expected of a decay factor (Vindry et al. 2017). The up-regulated transcripts tended to be AU-rich, in both CDS and 3'UTR, with binding sites for the ARE-binding proteins TTP and HuR. Furthermore, these transcripts largely overlapped with those accumulating in P-bodies in untreated cells (Fig. 4A). Yet, Pat1b silencing, which leads to the stabilization of these mRNAs, reduces P-body numbers (Hubstenberger et al. 2017; Vindry et al. 2017; Courel et al. 2018). As also seen in yeast (He et al. 2018), mRNAs up-regulated in Pat1b-depleted cells were largely distinct from those up-regulated in DDX6-depleted cells, which tended to be GC-rich and cytosolic (Fig. 4B). Thus, these two enhancers of decapping are not universal factors and act with some target specificity in both species. However, mRNAs up-regulated in Pat1b-depleted cells largely overlapped with those translationally activated by DDX6-depletion, suggesting a link between Pat1b-dependent mRNA decay and DDX6-dependent translation repression (Courel et al. 2018). In contrast, some mRNAs are particularly down-regulated after Pat1b silencing and remain excluded from P-bodies in normal conditions. Interestingly, these include most TOP and histone mRNAs, confirming that they are regulated by a distinct posttranscriptional mechanism, most likely related to the terminal oligopyrimidine motif present in TOP mRNA leader sequences and the unique $3^{\prime}$ termination mechanism of histone mRNAs which produces non-adenylated mRNAs (Fig. 4C). GO analysis of Pat1b up-regulated targets revealed the enrichment of mRNAs involved in RNA metabolic processes and RNA-binding functions. In contrast, the transcripts whose levels decreased upon Pat1b knockdown encoded proteins involved in developmental processes (Vindry et al. 2017). Altogether then, Pat1 and Dhh1/DDX6 proteins, though directly interacting in yeast and man (Sharif et al. 
2013; Ozgur et al. 2015), target distinct mRNAs for decay. In human cells, Pat1 targets are distinguished by being AU-rich, translationally repressed by DDX6 and enriched in P-bodies. Next, we discuss the pre-mRNA targets of human Pat1b.

\section{The role of Pat1b in alternative splicing}

Our mass spectroscopy studies revealed that nuclear Pat1b co-purifies with trisnRNP (U4/U6.U5), a spliceosome sub-complex which recycles after each splicing event (see Box 2). Pat1b stabilized the interactions between Lsm2-8 and the U6-associated protein SART3, setting up the Pat1b/Lsm2-8/U6 snRNA/SART3 axis, altogether suggesting that the role of Pat1b in the nucleus involves the splicing process (Vindry et al. 2017). These biochemical experiments were supported by a recent report which showed that Pat $1 p$ binding to U6 snRNP, specifically to Lsm2-8/U6 snRNA/Prp24 (yeast homologue of SART3) is structurally feasible (Montemayor et al. 2018). Additional support came from immunofluorescence experiments showing that Pat1b co-localizes with splicing speckles and with Cajal bodies, the sites of tri-snRNP assembly (Marnef et al. 2012; Vindry et al. 2017).

RNA-seq data obtained following Pat1b depletion identified 189 alternative splicing events, with more than $80 \%$ at the level of inclusion or skipping of cassette exons. As judged by the low frequency of intron retention events, global splicing efficiency was not affected. The relatively modest number of alternative splicing changes upon Pat1b silencing possibly reflected the minor proportion of nuclear Pat1b in proliferating HEK293 cells. Of the regulated casette exons, 85\% showed decreased inclusion upon Pat1b depletion. Interestingly, they had weak donor and acceptor splice sites compared to constitutive exons, suggesting that Pat1b enhances the inclusion of casette exons with sub-optimal donor and acceptor splice sites (Vindry et al. 2017). Our biochemical data indicated that Pat1b enhances a step in tri-snRNP assembly. We suggest that when these are abundant, the regulated exons are included, despite their weaker splice sites, possibly because the weak binding of early splicing factors including U2AF, U1 and U2 snRNPs is rapidly stabilized by subsequent binding of tri-snRNP. Consistent with this possibility, the Pat1b-regulated exons are flanked by particularly short introns, which would therefore be transcribed faster than normal, leading to reduced recognition of weak splice sites when tri-snRNP levels are reduced. Our model proposes that Pat $1 b$, which by virtue of its interactions with tri-snRNP likely acts late in splicing cycle, can nevertheless affect splice site choice (Fig.5). 
Pat1's role in splicing is also suggested by a recent study investigating the reduced spliceosome in Cyanidioschyzo merolae, an organism with only 27 introns (Reimer et al. 2017). Interestingly, the sole Lsm complex in the red alga, Lsm1-7, copurifies with Pat1 and tri-snRNP components including proteins and snRNAs. Whether yeast Pat1p participates in splicing is not known, though as mentioned earlier, it is a shuttling protein (Teixeira and Parker 2007) and co-isolates with the penta-snRNP (Stevens et al. 2002). Pat1p may have additional nuclear roles as $S$. cerevisae has relatively reduced splicing and no alternative splicing events have been described. Indeed, in view of the yeast Lsm2-8 functions in pretRNA and rRNA processing (Kufel et al. 2002; Kufel et al. 2003), Pat1p may participate in the latter as reported recently (Muppavarapu et al. 2016), though a prior study did not find evidence for Pat1p's involvement in ribosome biogenesis (Bonnerot et al. 2000).

\section{Additional roles of Pat1 proteins: translation inhibition}

In yeast, Pat1p co-deletion together with Dhh1 prevents the inhibition in protein synthesis seen following glucose starvation, while the single deletion mutants showed modest impairment in polysome profiles (Coller and Parker 2005). When overexpressed in vivo and in vitro, Pat1p repressed translation, largely mediated by $M$ and PatC domains (Fig. 2) which limit the interaction of the $43 \mathrm{~S}$ pre-initiation complex with mRNA, thus at or prior to the initiation step (Coller and Parker 2005; Pilkington and Parker 2008; Nissan et al. 2010).

The tethered function approach in Xenopus oocytes indicated that both XPat1a and $x$ Pat1b repress translation of the reporter mRNA, without resulting in its decay (Marnef et al. 2010; Nakamura et al. 2010). This was not altogether surprising as decapping activity is very low or absent in Xenopus as well as in mouse oocytes (Gillian-Daniel et al. 1998; Zhang et al. 1999; Ma et al. 2013).

However, the same approach in human cell lines, with robust decapping, did not show any evidence of significant translational repression by hPat1b (Ozgur et al. 2010; Kamenska et al. 2014), suggesting that this function may only be revealed when decapping is absent. It would be very insightful to perform polysome profiling assays in Pat1b-depleted cells to reveal the extent of its translational repressive activity. Surprisingly, tethered hPat1a, normally not expressed in cell lines, was inert in these tests, suggesting that it could neither repress nor decay the bound mRNA in contrast to XPat1a's repression in oocytes (Ozgur et al. 2010; Kamenska et al. 2014). This could reflect the difference in cellular context 
or a difference in protein partners - for example DDX6 binds the Xenopus but not the human Pat1a protein. The hypothesis that Pat1's repressive activity requires, at least in part, its ability to bind DDX6 is supported by the yeast deletion studies. Moreover, while M and PatC were the most effective domains in repression, the $\mathrm{N}$-terminal domain which binds Dhh1/DDX6 was also inhibitory (Nissan et al. 2010).

Yeast Pat1p affects translation initiation, and intriguingly, we noted that human Pat1b co-purifies with eIF4B and several elF2 and eIF3 subunits associated with mRNA and the 435 complex, but no other initiation factors (Vindry et al. 2017). While the exact mechanism underlying Pat1 translational repression activity remains to be clarified, it is tempting to propose that Pat1 proteins act in steps to down-regulate gene expression - first by inhibiting translation initiation in association with DDX6, releasing elF4F from the cap and hence allowing the decapping enzyme access, leading to cap removal, and as indicated earlier, subsequently to $3^{\prime}-5^{\prime}$ decay.

\section{Evolutionary aspects of the Pat1/Lsm1-7 complex}

Yeast and human Pat1 proteins mediate mRNA decay, translational repression and nuclear RNA processing events including splicing and rRNA maturation. The mRNA decay and splicing processes in man are orchestrated in association with Lsm heptamer complexes, Lsm1-7 and Lsm2-8 respectively.

However, some organisms only have seven Lsm proteins altogether and their association with Pat1 proteins does not appear to be obligatory. Thus, C. merolae, mentioned earlier, only possess the Lsm1-7 heptamer which interacts with Pat1 and U6 SnRNA, and additional tri-snRNP components, and is thus likely to fulfil the splicing role. In addition, C.m. Lsm1-7 bind mRNA decay proteins including Dcp1/2 and Xrn1. As there is evidence that the C.m. Lsm proteins are not only nuclear but shuttle to the cytoplasm, they may therefore also participate in mRNA decay (Reimer et al. 2017). Kinetoplastids have a yet further reduced Lsm/Pat1 complex, in that they lack both Lsm1 and Pat1. The Lsm2-8 proteins are restricted to the nucleus, and likely mediate trans-splicing, as they interact with U6 snRNA (Tkacz et al. 2008; Tkacz et al. 2010; Kramer et al. 2012). The lack of a cytoplasmic Pat1/Lsm complex may be related to the entirely distinct decapping enzyme that operates in trypanosoma. In the place of the nudix hydrolase Dcp1/2 enzyme, T. brucei rely on the 
ApaH-like phosphatase TbALPH1 to remove the highly methylated caps from mRNA ((Kramer 2017); reviewed (Kramer and McLennan 2019)).

The Pat1/Lsm complex is thus relatively flexible in composition and spans multiple functions. Indeed, in stark contrast to the negative effects of Lsm1-7/Pat1 on mRNA stability for example, this cellular complex sequentially promotes viral translation and replication, as shown for Bromo Mosaic Virus in S. cerevisiae cells. It appears that the positive effect of the complex on viral translation requires its RNA-binding activity, but how this mediates BMV RNA circularization to faciliate translation is not clear. Regarding replication, at least four positive strand viruses infecting plants, insects and humans rely on the Pat1/Lsm1-7 complex (Jungfleisch et al. 2015); reviewed (Jungfleisch et al. 2016)). Interestingly, the bacterial Lsm1 homologue, $\mathrm{Hfq}$, which forms hexameric rings, has been characterized as the host factor for RNA bacteriophage Qb replication. Significantly, Its principal role is to chaperone RNA-RNA interactions between regulatory small RNAs and target mRNAs, to alter mRNA translation and/or stability (Updegrove et al. 2016). Altogether, Lsm and related proteins, in the form of hexa/hepta rings, universally mediate RNA-protein, and RNA-RNA interactions to principally regulate mRNA levels, and other processes, and in yeasts and metazoa, they do so in complex with Pat1 proteins.

\section{Conclusion}

Yeast Pat1p and human Pat1b RNA-binding proteins have been extensively characterized, and largely share protein co-factors and a common role in decapping and subsequent cytoplasmic mRNA decay, in concert with the heptameric ring Lsm1-7. Interestingly, their mRNA targets do not overlap with the targets of another decapping co-factor, the conserved Dhh1/DDX6 RNA helicase. In man, Pat1b susceptible mRNAs are AU-rich in general and indeed many bear ARE elements, presumably reflecting the preference of this RNA-binding protein family for $\mathrm{U}$ and $\mathrm{A}$ tracts. At steady state, the large majority of Pat1 proteins are cytoplasmic, and found enriched in P-bodies. They also shuttle between the nucleus and cytoplasm in a Crm1-dependent manner, and are components of several types of nuclear RNP granules including Cajal bodies, splicing speckles and PML bodies. Nuclear Pat1b influences splice site choice together with Lsm2-8, illustrating the wide range of functions that can be mediated by paralogous complexes. However, there is essentially no overlap between Pat1b targets in the cytoplasm and nucleus. This is not surprising, as Pat1 
proteins bind mRNAs at their $3^{\prime}$ ends in the cytoplasm while nuclear Pat1b interacts indirectly with U6 snRNA and SART3 to influence splice site choice. Furthermore, Pat1 proteins inhibit translation, and this may precede their participation in mRNA decay. Pat1 proteins act in collaboration with Lsm heptamer rings in both mRNA decay and alternative splicing, but whether this is also true for their translational repression function is not known. The close association between Pat1 and the Lsm ring and their function in mRNA decay and splicing appear to be evolutionarily conserved as illustrated by its presence in the red alga $C$. merolae, though interestingly this organism only possesses a total of seven Lsm proteins, indicating a degree of plasticity in the roles of the complex.

Among the important questions that remain to be addressed, some concern the principal role of the Pat1/Lsm1-7 complex in mRNA decay. Does the complex activate Dcp2 or just recruit it to mRNA? Indeed, considerable recent insight has been gained from structural and biochemical studies of fungal Dcp1/2 enzymes together with enhancers of decapping and cap analogs reviewed (Valkov et al. 2017). For example, S. pombe Edc3 has been shown to alleviate the autoinhibition of the catalytic step of Dcp1/2 and to promote its RNA binding (Paquette et al. 2018). Indeed, S. pombe Pat1 also alleviates this autoinhibition, and enhances substrate binding of Dcp1/2 (Lobel et al. 2019). However, as there are notable differences between yeast and human Dcp1/2 enzymes, do they impact Pat1 function? Or did Pat1 co-evolve with Dcp1/2, giving rise to the differences between yeast and human Pat1 proteins? In this regard, it is interesting to note that the HLM of fungal Dcp2 has been transferred to a long C-terminal extension of metazoan Dcp1 (Jonas and Izaurralde 2013).

Secondly, following decapping, do Pat1 proteins simulate mRNA decay 3'-5' only or both $3^{\prime}-5^{\prime}$ and $5^{\prime}-3^{\prime}$ ? Do both the exosome and Dis3L2 mediate the $3^{\prime}-5^{\prime}$ pathway? Moreover, where are Pat1b/Lsm1-7 mRNA targets decayed? Purified P-body mRNAs are intact (Hubstenberger et al. 2917) and ARE reporter mRNAs are not degraded in P-bodies (Horvathova et al. 2017), so these targets are stored rather than decayed in P-bodies. Is this due to the absence of the exosome? Or to an excessive molecular crowding in P-bodies? While the fraction of the Pat1b protein present in P-bodies has not been quantified, immunofluorescence studies suggest that it is low, so that the fraction active in decay may reside in the cytosol. 
Turning now to its nucleocytoplasmic shuttling, does it result in a cross-talk between Pat1b cytoplasmic and nuclear functions that is important for the coherence of the gene expression program? Does it also result in a cross-talk between cytosolic P-bodies and nuclear Cajal bodies? Are there particular conditions, physiological or pathological, where Pat1b is massively imported in the nucleus to impact splicing more than mRNA decay? Altogether, while substantial knowledge and understanding of the architecture, co-factors and functions the Pat1 RNA-binding protein family has been reached, manifestly future investigations along these lines will be insightful and of considerable interest. 


\section{Figure and Table Legends}

(Wurm et al. 2016)

Figure 1

Pat1 proteins. A. Table of Pat1 proteins with names and length in amino acids. B. Cartoon indicating the differential expression of XPat1a and XPat1b during Xenopus oogenesis and embryogenesis.

\section{Figure 2}

Domain architecture and binding partners of yeast and human Pat1 proteins. Structures of portions of N-ter and C-ter domains of yeast Pat1p with Dhh1 (PDB 4brw; (Sharif et al. 2013)), Lsm1-7 (PDB 4C8Q; (Sharif and Conti 2013)) and Dcp2 (PDB 5LM5; (Charenton et al. 2017)) are shown.

\section{Figure 3}

Cellular distribution of human Pat1b in granules. Schematic cartoon indicating sub-cellular localization of GFP-Pat1b and GFP-Pat1b-NES* (with inactivated NES) in cytoplasmic Pbodies and nuclear Cajal bodies, splicing speckles and PML bodies in HeLa cells.

\section{Figure 4}

Pat1b tends to degrade AU-rich mRNAs which are resident in P-bodies, unlike DDX6 which decays GC-rich mRNAs. A. mRNA enrichment in P-bodies purified from non-stressed HEK293 cells (Hubstenberger et al. 2017) was expressed as a function of mRNA fold-changes after PAT1B silencing (Vindry et al. 2017). All mRNAs (14730) are in grey, while mRNAs with a GC content lower than $40 \%$ (2124) are in red. B. mRNAs were subdivided into six classes depending on the GC content of their gene (from $<40$ to $>60 \%$ ). The boxplots represent the distribution of their respective fold-changes after PAT1B (in orange, (Vindry et al. 2017)) or DDX6 (in green, (Hubstenberger et al. 2017)) silencing. The boxes represent the 25-75 percentiles and the whiskers the $10-90$ percentiles. $r_{S}$ is the Spearman correlation coefficient. C. Same as A with TOP (left panel) and histone (right panel) mRNAs in red (Courel et al. 2018). 
Figure 5

Summary model of Pat1b's functions in cytoplasmic mRNA decay and nuclear alternative splicing, via Lsm1-7 and Lsm2-8 respectively.

Table 1

Table of Pat1 protein interacting proteins in fungi, flies, Xenopus and man

\section{Funding Information}

This work was supported by the BBSRC, Newton Trust and Foundation Wiener - Anspach (C.V.) to N.S.'s laboratory, and the Association pour la Recherche sur le Cancer and the Agence Nationale pour la Recherche contract ANR-14-CE09-0013-01 to D.W.'s laboratory. 


\section{References}

Alhusaini N, Coller J. 2016. The deadenylase components Not2p, Not3p, and Not5p promote mRNA decapping. RNA 22: 709-721.

Ayache J, Bénard M, Ernoult-Lange M, Minshall N, Standart N, Kress M, Weil D. 2015. P-body assembly requires DDX6 repression complexes rather than decay or Ataxin $2 / 2 \mathrm{~L}$ complexes. Mol Biol Cell 26: 2579-2595.

Baltz AG, Munschauer M, Schwanhäusser B, Vasile A, Murakawa Y, Schueler M, Youngs N, Penfold-Brown D, Drew K, Milek M et al. 2012. The mRNA-Bound Proteome and Its Global Occupancy Profile on Protein-Coding Transcripts. Mol Cell 46: 674-690.

Barišić-Jäger E, Kręcioch I, Hosiner S, Antic S, Dorner S. 2013. HPat a Decapping Activator Interacting with the miRNA Effector Complex. PLos ONE 8: e71860.

Beckmann BM, Horos R, Fischer B, Castello A, Eichelbaum K, Alleaume AM, Schwarzl T, Curk T, Foehr S, Huber W et al. 2015. The RNA-binding proteomes from yeast to man harbour conserved enigmRBPs. Nat Commun 6: 10127.

Beggs JD. 2005. Lsm proteins and RNA processing. Bioch Soc Trans 33: 433-438.

Boeck R, Lapeyre B, Brown CE, Sachs AB. 1998. Capped mRNA degradation intermediates accumulate in the yeast spb8-2 mutant. Mol Cell Biol 18: 5062-5072.

Bonnerot C, Boeck R, Lapeyre B. 2000. The Two Proteins Pat1p (Mrt1p) and Spb8p Interact In Vivo, Are Required for mRNA Decay, and Are Functionally Linked to Pab1p. Mol Cell Biol 20: 5939-5946.

Bouveret E, Rigaut G, Shevchenko A, Wilm M, Séraphin B. 2000. A Sm-like protein complex that participates in mRNA degradation. EMBO J 19: 1661-1671.

Brandmann T, Fakim H, Padamsi Z, Youn JY, Gingras AC, Fabian MR, Jinek M. 2018. Molecular architecture of LSM14 interactions involved in the assembly of mRNA silencing complexes. EMBO J 37: e97869.

Braun JE, Tritschler F, Haas G, Igreja C, Truffault V, Weichenrieder O, Izaurralde E. 2010. The C-terminal alpha-alpha superhelix of Pat is required for mRNA decapping in metazoa. EMBO J 29: 2368-2380.

Castello A, Fischer B, Eichelbaum K, Horos R, Beckmann BM, Strein C, Davey NE, Humphreys DT, Preiss T, Steinmetz LM et al. 2012. Insights into RNA Biology from an Atlas of Mammalian mRNA-Binding Proteins. Cell 149: 1393-1406.

Castello A, Frese CK, Fischer B, Järvelin AI, Horos R, Alleaume AM, Foehr S, Curk T, Krijgsveld J, Hentze MW. 2017. Identification of RNA-binding domains of RNA-binding proteins in cultured cells on a system-wide scale with RBDmap. Nat Protoc 12: 2447-2464.

Chang CT, Bercovich N, Loh B, Jonas S, Izaurralde E. 2014. The activation of the decapping enzyme DCP2 by DCP1 occurs on the EDC4 scaffold and involves a conserved loop in DCP1. Nucleic Acids Res 42: 5217-5233.

Charenton C, Gaudon-Plesse C, Fourat iZ, Taverniti V, Back R, Kolesnikova O, Séraphin B, Graille M. 2017. A unique surface on Pat1 C-terminal domain directly interacts with Dcp2 decapping enzyme and Xrn1 5'-3' mRNA exonuclease in yeast. PNAS 114: E9493-E9501.

Charenton C, Graille M. 2018. mRNA decapping: finding the right structures. Philos Trans $R$ Soc Lond B Biol Sci 373: 20180164.

Chen B, Zhang Z, Sun X, Kuang Y, Mao X, Wang X, Yan Z, Li B, Xu Y, Yu M et al. 2017. Biallelic Mutations in PATL2 Cause Female Infertility Characterized by Oocyte Maturation Arrest. Am J Hum Genet 101: 609-615. 
Chowdhury A, Kalurupalle S, Tharun S. 2014. Pat1 contributes to the RNA binding activity of the Lsm1-7-Pat1 complex. RNA 20: 1465-1470.

Chowdhury A, Mukhopadhyay J, Tharun S. 2007. The decapping activator Lsm1p-7p-Pat1p complex has the intrinsic ability to distinguish between oligoadenylated and polyadenylated RNAs. RNA 13: 998-1016.

Chowdhury A, Raju KK, Kalurupalle S, Tharun S. 2012. Both Sm-domain and C-terminal extension of Lsm1 are important for the RNA-binding activity of the Lsm1-7-Pat1 complex. RNA 18: 936-944.

Christou-Kent M, Kherraf ZE, Amiri-Yekta A, Le Blévec E, Karaouzène T, Conne B, Escoffier J, Assou S, Guttin A, Lambert E et al. 2018. PATL2 is a key actor of oocyte maturation whose invalidation causes infertility in women and mice. EMBO Mol Med 10: e8515.

Coller J, Parker R. 2005. General translational repression by activators of mRNA decapping. Cell 122: 875-886.

Courel $M$, Clément $Y$, Foretek D, Vidal O, Yi Z, Kress $M$, Vindry C, Bénard M, Bossevain C, Antoniewski $C$ et al. 2018. GC content shapes mRNA decay and storage in human cells. Biorxiv 10.1101/373498.

De Almeida C, Scheer H, Zuber H, Gagliardi D. 2018. RNA uridylation: a key posttranscriptional modification shaping the coding and noncoding transcriptome. Wiley Interdiscip Rev RNA 9: 10.1002/wrna.

Decker CJ, Parker R. 1993. A turnover pathway for both stable and unstable mRNAs in yeast: evidence for a requirement for deadenylation. Genes Dev 7: 1632-1643.

Ditlev JA, Case LB, Rosen MK. 2018. Who's In and Who's Out-Compositional Control of Biomolecular Condensates. J Mol Biol 430: 4666-4684.

Dostie J, Ferraiuolo M, Pause A, Adam SA, Sonenberg N. 2000. A novel shuttling protein, 4E$\mathrm{T}$, mediates the nuclear import of the mRNA $5^{\prime}$ cap-binding protein, elF4E. EMBO J 19: 3142-3156.

Fromont-Racine M, Mayes AE, Brunet-Simon A, Rain JC, Colley A, Dix I, Decourty L, Joly N, Ricard F, Beggs JD et al. 2000. Genome-wide protein interaction screens reveal functional networks involving Sm-like proteins. Yeast 17: 95-110.

Garre E, Pelechano V, Sánchez Del Pino M, Alepuz P, Sunnerhagen P. 2018. The Lsm1-7/Pat1 complex binds to stress-activated mRNAs and modulates the response to hyperosmotic shock. PLoS Genet 14: e1007563.

Gatica D, Hu G, Liu X, Zhang N, Williamson PR, Klionsky DJ. 2019. The Pat1-Lsm Complex Stabilizes ATG mRNA during Nitrogen Starvation-Induced Autophagy. Mol Cell 73: 314-324.

Gillian-Daniel DL, Gray NK, Astrom J, Barkoff A, Wickens M. 1998. Modifications of the 5' cap of mRNAs during Xenopus oocyte maturation: independence from changes in poly(A) length and impact on translation. Mol Cell Biol 18: 6152-6153.

Grudzien-Nogalska E, Kiledjian M. 2017. New insights into decapping enzymes and selective mRNA decay. Wiley Interdiscip Rev RNA 8: 10.1002/wrna.1379.

Haas G, Braun JE, Igreja C, Tritschler F, Nishihara T, Izaurralde E. 2010. HPat provides a link between deadenylation and decapping in metazoa. J Cell Biol 189: 289-302.

Havugimana PC, Hart GT, Nepusz T, Yang H, Turinsky AL, Li Z, Wang PI, Boutz DR, Fong V, Phanse $S$ et al. 2012. A census of human soluble protein complexes. Cell 150: 10681081.

He F, Celik A, Wu C, Jacobson A. 2018. General decapping activators target different subsets of inefficiently translated mRNAs. Elife 7: e34409. 
He F, Jacobson A. 2015. Control of mRNA decapping by positive and negative regulatory elements in the Dcp2 C-terminal domain. RNA 21: 1633-1647.

Hentze MW, Castello A, Schwarzl T, Preiss T. 2018. A brave new world of RNA-binding proteins. Nat Rev Mol Cell Biol 19: 327-341.

Horvathova I, Voigt F, Kotrys AV, Zhan Y, Artus-Revel CG, Eglinger J, Stadler MB, Giorgetti L, Chao JA. 2017. The Dynamics of mRNA Turnover Revealed by Single-Molecule Imaging in Single Cells. Mol Cell 68: 615-625.

Huang JH, Ku WC, Chen YC, Chang YL, Chu C. 2017. Dual mechanisms regulate the nucleocytoplasmic localization of human DDX6. Sci Rep 7: 42853.

Huang L, Tong X, Wang F, Luo L, Jin R, Fu Y, Zhou G, Li D, Song G, Liu Y et al. 2018. Novel mutations in PATL2 cause female infertility with oocyte germinal vesicle arrest. Hum Reprod 33: 1183-1190.

Hubstenberger $A$, Courel $M$, Bénard $M$, Souquère $S$, Ernoult-Lange $M$, Chouaib $R, Y i$, Morlot J-B, Munier A, Fradet $M$ et al. 2017. P-body purification reveals the condensation of repressed mRNA regulons. Molecular Cell 68: 144-157.

Hubstenberger A, Courel M, Bénard M, Souquere S, Ernoult-Lange M, Chouaib R, Yi Z, Morlot JB, Munier A, Fradet M et al. 2917. P-Body Purification Reveals the Condensation of Repressed mRNA Regulons. Mol Cell 68: 144-157.

Jonas S, Izaurralde E. 2013. The role of disordered protein regions in the assembly of decapping complexes and RNP granules. Genes and Dev 27: 2628-2641.

Jungfleisch J, Blasco-Moreno B, Díez J. 2016. Use of Cellular Decapping Activators by Positive-Strand RNA Viruses. Viruses 8: E340.

Jungfleisch J, Chowdhury A, Alves-Rodrigues I, Tharun S, Díez J. 2015. The Lsm1-7-Pat1 complex promotes viral RNA translation and replication by differential mechanisms. RNA 21: 1469-1479.

Kamath RS, Fraser AG, Dong Y, Poulin G, Durbin R, Gotta M, Kanapin A, Le Bot N, Moreno S, Sohrmann $\mathrm{M}$ et al. 2003. Systematic functional analysis of the Caenorhabditis elegans genome using RNAi. Nature 421: 231-237.

Kamenska A, Lu W-T, Kubacka D, Broomhead H, Minshall N, Bushell M, Standart N. 2014. Human 4E-T represses translation of bound mRNAs and enhances microRNAmediated silencing. Nucleic Acids Res 42: 3298-3313.

Kamenska A, Simpson C, Vindry C, Broomhead H, Bénard M, Ernoult-Lange M, Lee BP, Harries LW, Weil D, Standart N. 2016. The DDX6-4E-T interaction mediates translational repression and P-body assembly. Nucleic Acids Res 44: 6318-6334.

Kırlı K, Karaca S, Dehne HJ, Samwer M, Pan KT, Lenz C, Urlaub H, Görlich D. 2015. A deep proteomics perspective on CRM1-mediated nuclear export and nucleocytoplasmic partitioning. Elife 4: e11466.

Kramer S. 2017. The ApaH-like phosphatase TbALPH1 is the major mRNA decapping enzyme of trypanosomes. PLoS Pathog 13: e1006456.

Kramer S, Marnef A, Standart N, Carrington M. 2012. Inhibition of mRNA maturation in trypanosomes causes the formation of novel foci at the nuclear periphery containing cytoplasmic regulators of mRNA fate. I Cell Sci 125: 2896-2909.

Kramer S, McLennan AG. 2019. The complex enzymology of mRNA decapping: Enzymes of four classes cleave pyrophosphate bonds. Wiley Interdiscip Rev RNA 10: e1512.

Kufel J, Allmang C, Petfalski E, Beggs J, Tollervey D. 2003. Lsm Proteins are required for normal processing and stability of ribosomal RNAs. J Biol Chem 278: 2147-2156. 
Kufel J, Allmang C, Verdone L, Beggs JD, Tollervey D. 2002. Lsm proteins are required for normal processing of pre-tRNAs and their efficient association with La-homologous protein Lhp1p. Mol Cell Biol 22: 5248-5256.

Łabno A, Tomecki R, Dziembowski A. 2016. Biochim Biophys Acta 1863: 3125-3147.

Liao Y, Castello A, Fischer B, Leicht S, Föehr S, Frese CK, Ragan C, Kurscheid S, Pagler E, Yang $\mathrm{H}$ et al. 2016. The Cardiomyocyte RNA-Binding Proteome: Links to Intermediary Metabolism and Heart Disease. Cell Rep 16: 1456-1469.

Lobel JH, Tibble RW, Gross JD. 2019. Pat1 activates late steps in mRNA decay by multiple mechanisms. Biorxiv https://doi.org/10.1101/594168.

Luo Y, Na Z, Slavoff SA. 2018. P-Bodies: Composition, Properties, and Functions. Biochemistry 57: 2424-2431.

Ma J, Flemr M, Strnad H, Svoboda P, Schultz RM. 2013. Maternally recruited DCP1A and DCP2 contribute to messenger RNA degradation during oocyte maturation and genome activation in mouse. Biol Reprod 88: 11.

Maddirevula S, Coskun S, Alhassan S, Elnour A, Alsaif HS, Ibrahim N, Abdulwahab F, Arold ST, Alkuraya FS. 2017. Female Infertility Caused by Mutations in the Oocyte-Specific Translational Repressor PATL2. Am J Hum Genet 101: 603-608.

Malecki M, Viegas SC, Carneiro T, Golik P, Dressaire C, Ferreira MG, Arraiano CM. 2013. The exoribonuclease Dis3L2 defines a novel eukaryotic RNA degradation pathway. EMBO J 32: 1842-1854.

Marnef A, Maldonado M, Bugaut A, Balasubramanian S, Kress M, Weil D, Standart N. 2010. Distinct functions of maternal and somatic Pat1 protein paralogs. RNA 16: 20942107.

Marnef A, Standart N. 2010. Pat1 proteins: a life in translation, translation repression and mRNA decay Bioch Soc Trans 38: 1602-1607.

Marnef A, Weil D, Standart N. 2012. RNA-related nuclear functions of human Pat1b, the Pbody mRNA decay factor. Mol Biol Cell 23: 213-224.

Minshall N, Reiter M-H, Weil D, Standart N. 2007. CPEB interacts with an ovary-specific elF4E and 4E-T in early Xenopus oocytes. J Biol Chem 282: 37389-37401.

Mitchell SF, Jain S, She M, Parker R. 2013. Global analysis of yeast mRNPs. Nat Struct Mol Biol 20: 127-133.

Montemayor EJ, Didychuk AL, Yake AD, Sidhu GK, Brow DA, Butcher SE. 2018. Architecture of the U6 snRNP reveals specific recognition of 3'-end processed U6 snRNA. Nat Commun 9: 1749.

Muppavarapu M, Huch S, Nissan T. 2016. The cytoplasmic mRNA degradation factor Pat1 is required for rRNA processing. RNA Biol 13: 455-465.

Nakamura Y, Tanaka KJ, Miyauchi M, Huang L, Tsujimoto M, Matsumoto K. 2010. Translational repression by the oocyte-specific protein P100 in Xenopus. Dev Biol 344: 272-283.

Nishihara T, Zekri L, Braun JE, Izaurralde E. 2013. miRISC recruits decapping factors to miRNA targets to enhance their degradation. Nucleic Acids Res 41: 8692-8705.

Nishimura T, Padamsi Z, Fakim H, Milette S, Dunham WH, Gingras AC, Fabian MR. 2015. The elF4E-Binding Protein 4E-T Is a Component of the mRNA Decay Machinery that Bridges the 5' and 3' Termini of Target mRNAs. Cell Rep 11: 1425-1436.

Nissan T, Rajyaguru P, She M, Song H, Parker R. 2010. Decapping activators in Saccharomyces cerevisiae act by multiple mechanisms. Mol Cell 39: 773-783. 
Ozgur S, Basquin J, Kamenska A, Filipowicz W, Standart N, Conti E. 2015. Structure of a human 4E-T - DDX6 - CNOT1 complex reveals the different interplay of DDX6binding proteins with the CCR4-NOT complex. Cell Reports 13: 703-711.

Ozgur S, Chekulaeva M, Stoecklin G. 2010. Human Pat1b connects deadenylation with mRNA decapping and controls the assembly of Processing-bodies. Mol Cell Biol 30: 4308-4323.

Paquette DR, Tibble RW, Daifuku TS, Gross JD. 2018. Control of mRNA decapping by autoinhibition. Nucleic Acids Res 46: 6318-6329.

Pilkington GR, Parker R. 2008. Pat1 contains distinct functional domains that promote Pbody assembly and activation of decapping. Mol Cell Biol 28: 1298-1312.

Pradhan SJ, Nesler KR, Rosen SF, Kato Y, Nakamura A, Ramaswami M, Barbee SA. 2012. The conserved $\mathrm{P}$ body component HPat/Pat1 negatively regulates synaptic terminal growth at the larval Drosophila neuromuscular junction. J Cell Sci 125: 6105-6116.

Presnyak V, Coller J. 2013. The DHH1/RCKp54 family of helicases: an ancient family of proteins that promote translational silencing. Presnyak V, Coller J 1829: 817-823.

Protter DSW, Rao BS, Van Treeck B, Lin Y, Mizoue L, Rosen MK, Parker R. 2018. Intrinsically Disordered Regions Can Contribute Promiscuous Interactions to RNP Granule Assembly. Cell Rep 22: 1401-1412.

Queiroz RML, Smith T, Villanueva E, Marti-Solano M, Monti M, Pizzinga M, Mirea D-M, Ramakrishna M, Harvey RF, Dezi V et al. 2019. Comprehensive identification of RNAprotein interactions in any organism using orthogonal organic phase separation (OOPS). Nat Biotechnol 37: 169-178.

Ramachandran V, Shah KH, Herman PK. 2011. The cAMP-dependent protein kinase signaling pathway is a key regulator of $P$ body foci formation. Mol Cell 43: 973-981.

Reimer KA, Stark MR, Aguilar LC, Stark SR, Burke RD, Moore J, Fahlman RP, Yip CK, Kuroiwa $H$, Oeffinger $M$ et al. 2017. The sole LSm complex in Cyanidioschyzon merolae associates with pre-mRNA splicing and mRNA degradation factors. RNA 23: 952-967.

Sachdev R, Hondele M, Linsenmeier M, Vallotton P, Mugler CF, Arosio P, K. W. 2019. Pat1 promotes processing body assembly by enhancing the phase separation of the DEAD-box ATPase Dhh1 and RNA. Elife e41415.

Scott DD, Norbury CJ. 2013. RNA decay via 3' uridylation. Biochim Biophys Acta 1829: 516519.

Sharif H, Conti E. 2013. Architecture of the Lsm1-7-Pat1 complex: a conserved assembly in eukaryotic mRNA turnover. Cell Rep 5: 283-291.

Sharif H, Ozgur S, Sharma K, Basquin C, Urlaub H, Conti E. 2013. Structural analysis of the yeast Dhh1-Pat1 complex reveals how Dhh1 engages Pat1, Edc3 and RNA in mutually exclusive interactions. Nucleic Acids Res 41: 8377-8390.

Sheth U, Parker R. 2003. Decapping and decay of messenger RNA occur in cytoplasmic processing bodies. Science 300: 805-808.

Song MG, Kiledjian M. 2007. 3' Terminal oligo U-tract-mediated stimulation of decapping. RNA 13: 2356-2365.

Standart N, Weil D. 2018. P-Bodies: cytosolic droplets for coordinated mRNA storage. Trends Genet 34: 612-626.

Staněk D. 2016. Cajal body and snRNPs - friends with benefits. RNA Biol 14: 671-679.

Stevens SW, Ryan DE, Ge HY, Moore RE, Young MK, Lee TD, Abelson J. 2002. Composition and functional characterization of the yeast spliceosomal penta-snRNP. Mol Cell 9: 31-44. 
Teixeira D, Parker R. 2007. Analysis of P-Body Assembly in Saccharomyces cerevisiae. Mol Biol Cell 18: 2274-2287.

Tharun S. 2009. Lsm1-7-Pat1 complex: a link between 3' and 5'-ends in mRNA decay? RNA Biol 6: 1837-1848.

Tharun S, He WH, Mayes AE, Lennertz P, Beggs JD, Parker R. 2000. Yeast Sm-like proteins function in mRNA decapping and decay. Nature 404: 515-518.

Tkacz ID, Cohen S, Salmon-Divon M, Michaeli S. 2008. Identification of the heptameric Lsm complex that binds U6 snRNA in Trypanosoma brucei. Mol Biochem Parasitol 160: 22-31.

Tkacz ID, Gupta SK, Volkov V, Romano M, Haham T, Tulinski P, Lebenthal I, Michaeli S. 2010. Analysis of spliceosomal proteins in Trypanosomatids reveals novel functions in mRNA processing. J Biol Chem 285: 27982-27999.

Totaro A, Renzi F, La Fata G, Mattioli C, Raabe M, Urlaub H, Achsel T. 2011. The human Pat1b protein: a novel mRNA deadenylation factor identified by a new immunoprecipitation technique. Nucleic Acids Res 39: 634-647.

Tritschler F, Braun JE, Eulalio A, Truffault V, Izaurralde E, Weichenrieder O. 2009. Structural basis for the mutually exclusive anchoring of $\mathrm{P}$ body components EDC3 and Tral to the DEAD box protein DDX6/Me31B. Mol Cell 33: 661-668.

Updegrove TB, Zhang A, Storz G. 2016. Hfq: the flexible RNA matchmaker. Curr Opin Microbiol 30: 133-138.

Valkov E, Jonas S, Weichenrieder O. 2017. Mille viae in eukaryotic mRNA decapping. Curr Opin Struct Biol 47: 40-51.

Vindry C, Marnef A, Broomhead H, Twyffels L, Ozgur S, Stoecklin G, Llorian M, Smith CW, Mata J, Weil D et al. 2017. Dual RNA Processing Roles of Pat1b via Cytoplasmic Lsm17 and Nuclear Lsm2-8 Complexes. Cell Rep 20: 1187-1200.

Wang CY, Wang YT, Hsiao WY, Wang SW. 2017. Involvement of fission yeast Pdc2 in RNA degradation and P-body function. RNA 23: 493-503.

Wang X, Watt PM, Louis EJ, Borts RH, Hickson ID. 1996. Pat1: a topoisomerase II-associated protein required for faithful chromosome transmission in Saccharomyces cerevisiae. Nucleic Acids Res 24: 4791-4797.

Wu D, Muhlrad D, Bowler MW, iang S, Liu Z, Parker R, Song H. 2014. Lsm2 and Lsm3 bridge the interaction of the Lsm1-7 complex with Pat1 for decapping activation. Cell Res 24: 233-246.

Wurm JP, Overbeck J, Sprangers R. 2016. The S. pombe mRNA decapping complex recruits cofactors and an Edc1-like activator through a single dynamic surface. RNA 22: 13601372.

Youn JY, Dunham WH, Hong SJ, Knight JDR, Bashkurov M, Chen GI, Bagci H, Rathod B, MacLeod G, Eng SWM et al. 2018. High-Density Proximity Mapping Reveals the Subcellular Organization of mRNA-Associated Granules and Bodies. Mol Cell 69: 517532.

Zhang S, Williams CJ, Wormington M, Stevens A, Peltz SW. 1999. Monitoring mRNA decapping activity. METHODS: A companion to Methods in Enzymology 17: 46-51.

Zhou L, Hang J, Zhou Y, Wan R, Lu G, Yin P, Yan C, Shi Y. 2014. Crystal structures of the Lsm complex bound to the $3^{\prime}$ end sequence of U6 small nuclear RNA. Nature 506: 116120. 


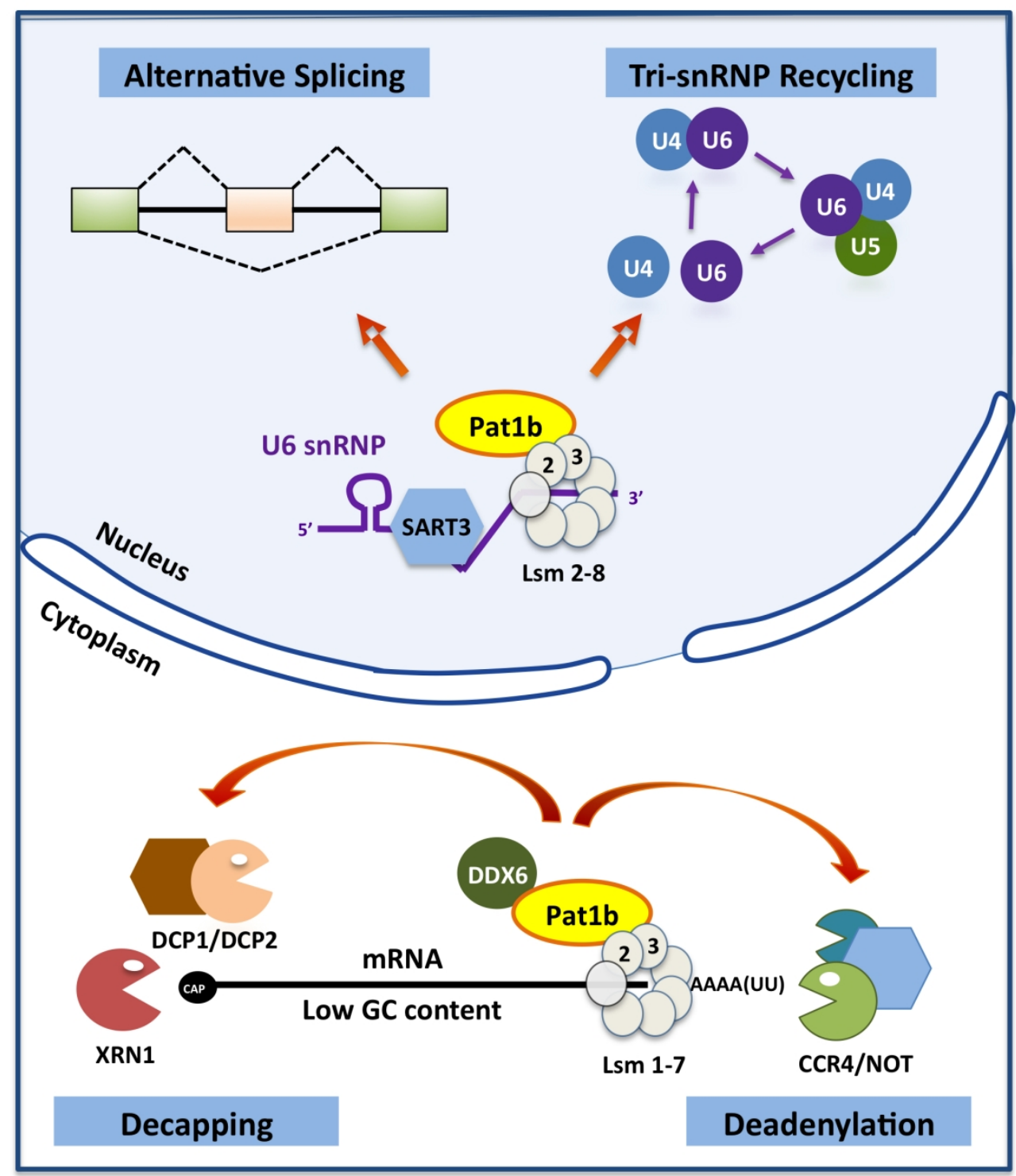

$166 \times 192 \mathrm{~mm}(300 \times 300 \mathrm{DPI})$ 
A

\begin{tabular}{|lllc|}
\hline \multicolumn{1}{|c}{ Organism } & \multicolumn{1}{c}{ Name } & \multicolumn{1}{c|}{ Full name } & Length (aa) \\
\hline S. cerevisiae & Pat1p & $\begin{array}{l}\text { Protein associated } \\
\text { with topoisomerase II }\end{array}$ & 796 \\
\hline S. pombe & Pdc2 & $\begin{array}{l}\text { Partner of decapping } \\
\text { enzyme protein 2 }\end{array}$ & 754 \\
\hline C. merolae & Pat1 & & 701 \\
\hline $\begin{array}{l}\text { D. } \text { melanogaster } \\
\text { C. } \text { elegans }\end{array}$ & PPat & Homologous to Pat1 & 968 \\
\hline X. laevis & $\begin{array}{l}\text { xPat1a/PATL2/P100 } \\
\text { xPat1b/PATL1 }\end{array}$ & Oocyte-specific & 833 \\
\hline H. sapiens & $\begin{array}{l}\text { Pat1a/PATL2 } \\
\text { Pat1b/PATL1 }\end{array}$ & Oocyte-specific & 733 \\
\hline
\end{tabular}




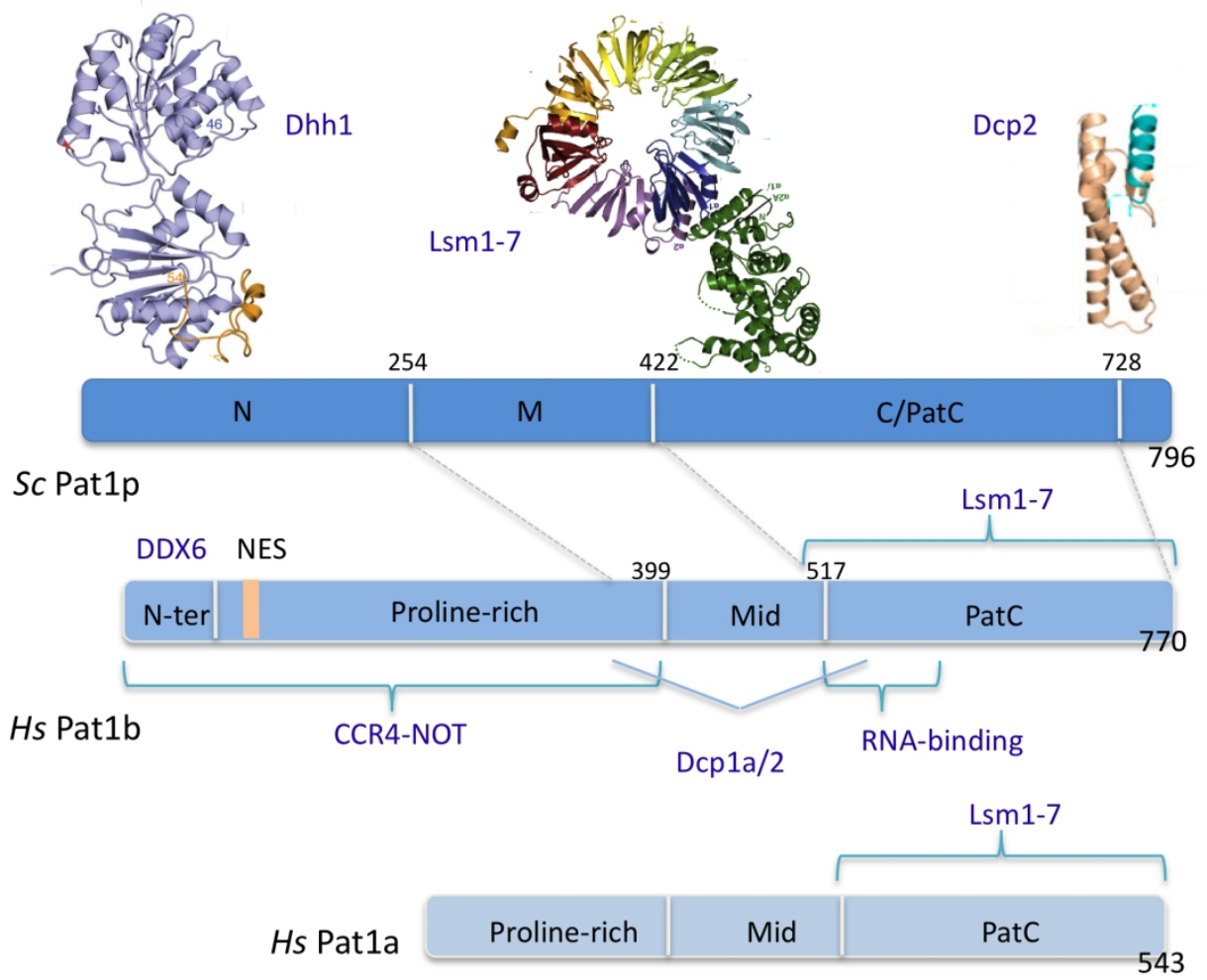

$171 \times 157 \mathrm{~mm}(300 \times 300$ DPI $)$

John Wiley \& Sons 


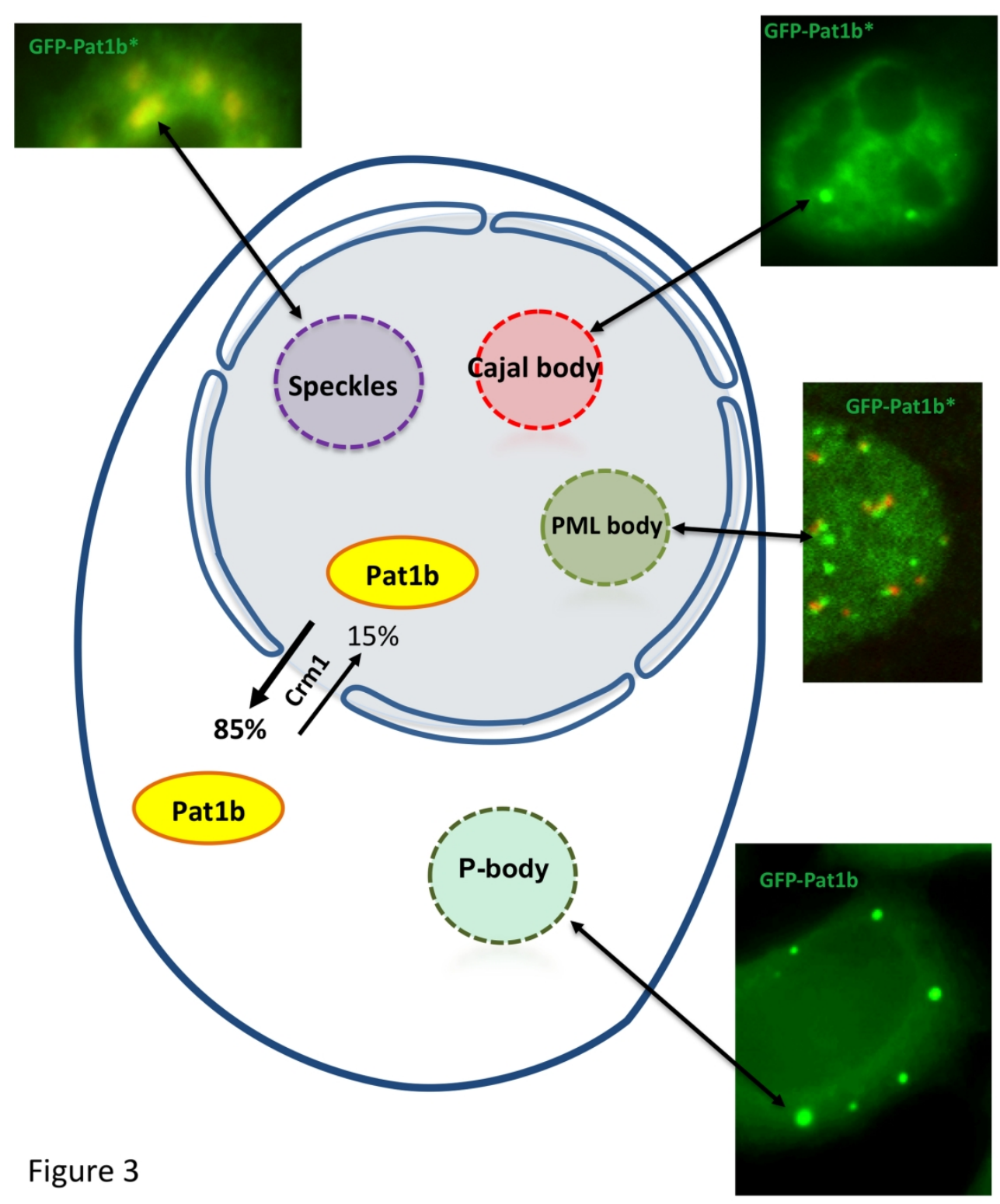

$173 \times 210 \mathrm{~mm}(300 \times 300 \mathrm{DPI})$ 

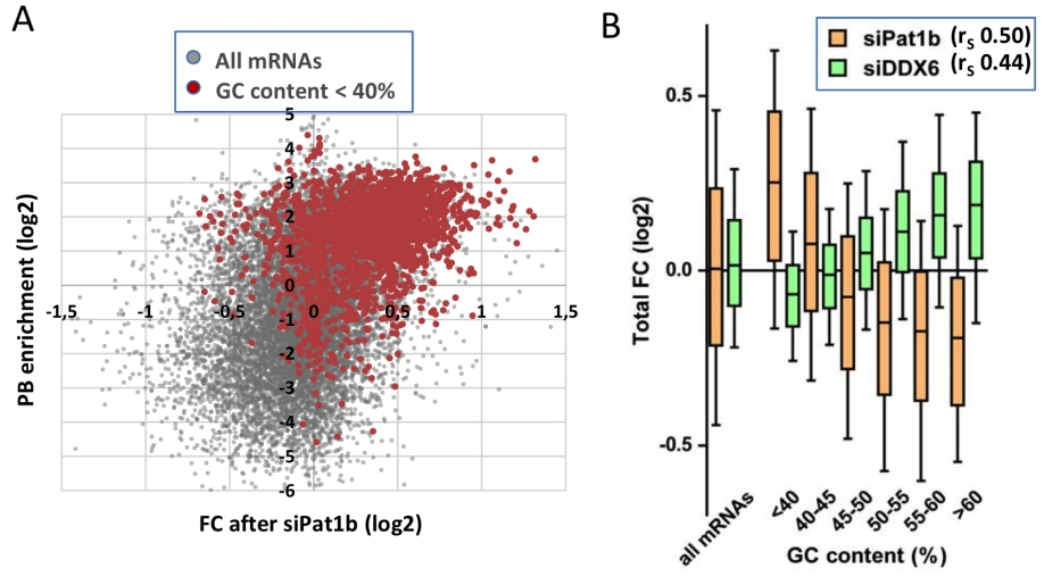

C

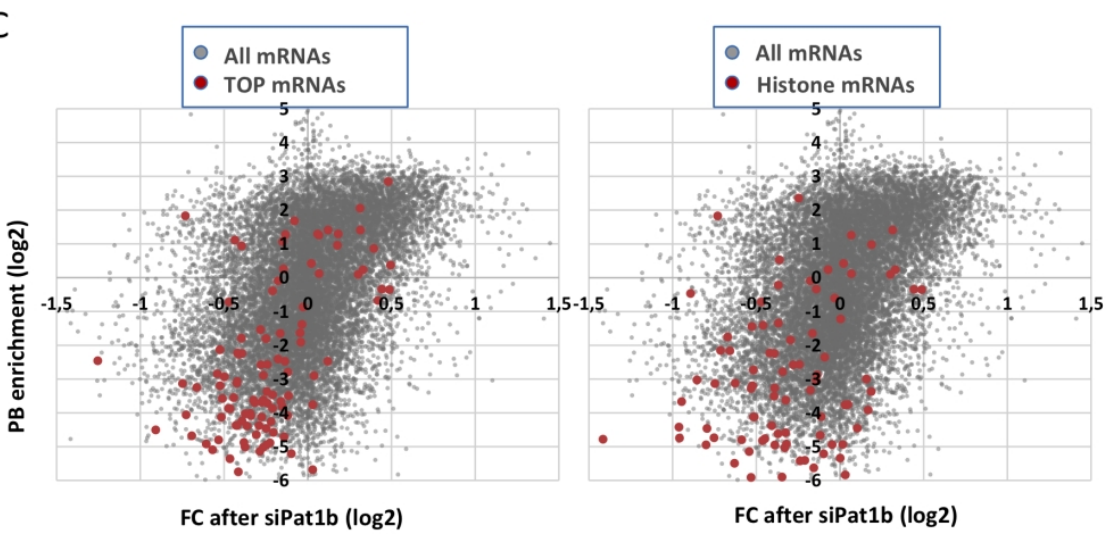

Figure 4

$168 \times 211 \mathrm{~mm}(300 \times 300 \mathrm{DPI})$

John Wiley \& Sons 


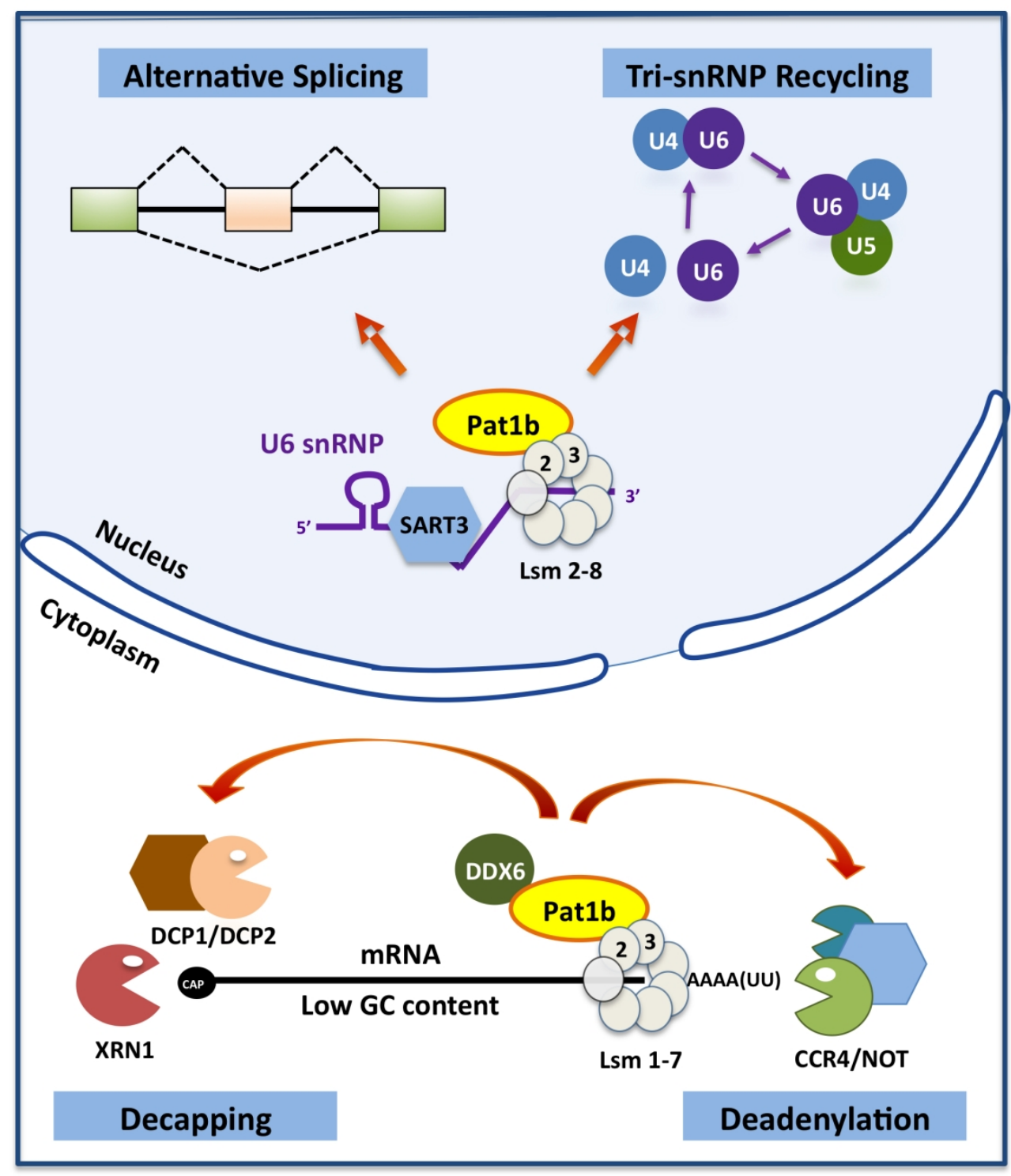

$166 \times 192 \mathrm{~mm}(300 \times 300 \mathrm{DPI})$ 


\begin{tabular}{|c|c|c|c|c|}
\hline $\begin{array}{l}\text { Binding } \\
\text { proteins }\end{array}$ & $\begin{array}{l}\text { Fungi } \\
\text { Pat1 }\end{array}$ & $\begin{array}{l}\text { Dm } \\
\text { HPat }\end{array}$ & $\begin{array}{c}\text { XI } \\
\text { Pat1a }\end{array}$ & $\begin{array}{c}\text { Hs } \\
\text { Pat1b }\end{array}$ \\
\hline Lsm1-7 & Sc Lsm1-7 $1-8$ & 15 & 18 & $22-25$ \\
\hline Lsm8 & Sc Lsm8 ${ }^{4}$ & & & 24,25 \\
\hline DDX6 & $\begin{array}{l}\text { Sc Dhh1 } 1^{3,6,9} \\
\text { Sp Ste13 }{ }^{10}\end{array}$ & $\mathrm{Me} 1 \mathrm{~B}^{15}$ & $\mathrm{Xp} 54^{18-21}$ & $19,22-25$ \\
\hline CCR4/NOT & Sc Not $3 / 5^{11}$ & Not $2,3,4,6,7^{15}$ & & $\begin{array}{l}\text { Not1 }{ }^{24} \\
\text { Not1-11 } 11^{25} \\
\text { Not1, } 6,7^{23}\end{array}$ \\
\hline Dcp1/2 & $\begin{array}{l}\text { Sc Dcp1/2 } 2^{5-6,12-13} \\
\text { Sp Dcp1/2 }\end{array}$ & $\mathrm{Dcp} 2^{15}$ & & Dcp1a/222-25 \\
\hline Xrn1 & $\begin{array}{l}\text { Sc Xrn1 } 1^{5,13} \\
\text { Sp Exo2 } 2^{10}\end{array}$ & & & $23-25$ \\
\hline Edc3 & $\begin{array}{l}\text { Sc Edc3 }{ }^{6} \\
\text { Sp Edc3 } 3^{10}\end{array}$ & & & $22-25$ \\
\hline Edc4 & na & & & $22-25$ \\
\hline Lsm14 & Sc Scd6 $6^{5}$ & & Lsm14B ${ }^{18,21}$ & Lsm14A/B 25,26 \\
\hline $4 \mathrm{E}-\mathrm{T}$ & na & & 18,21 & $24,27,28$ \\
\hline Ago/GW182 & na & 16,17 & & 24,25 \\
\hline tri-snRNP* & & & & $\begin{array}{l}\text { Prp3, } 4^{24,25,29} \\
\text { Prp6,8,19,31 }\end{array}$ \\
\hline
\end{tabular}

Table 1

$\begin{array}{ll}\text { 1. Bonneret et al. } 2000 & \text { 16. Barisic-Jager et al., } 2013 \\ \text { 2. Bouveret et al. } 2000 & \text { 17. Nishihara et al., 2013 } \\ \text { 3. Coller et al., } 2001 & \text { 18. Nakamura et al., 2010 } \\ \text { 4. Fromont-Racine et al., 2000 } & \text { 19. Ayache et al., 2015 } \\ \text { 5. Nissan et al., 2010 } & \text { 20. Marnef et al., 2010 } \\ \text { 6. Pilkington et al., 2008 } & \text { 21. Minshall et al., 2007 } \\ \text { 7. Sharif and Conti, 2013 } & \text { 22. Braun et al., 2010 } \\ \text { 8. Tharun et al., 2000 } & \text { 23. Ozgur et al., 2010 } \\ \text { 9. Sharif et al., 2013 } & \text { 24. Vindry et al., 2017 } \\ \text { 10. Wang et al., 2017 } & \text { 25. Youn et al., 2017 } \\ \text { 11. Alhusaini and Coller, 2016 } & \text { 26. Bradmann et al., 2018 } \\ \text { 12. He and Jacobson, 2015 } & \text { 27. Kamenska et al., 2016 } \\ \text { 13. Charenton et al., 2017 } & \text { 28. Nishimura et al., 2015 } \\ \text { 14. Wurm et al., 2016 } & \text { 29. Havugimina et al., 2012 } \\ \text { 15. Haas et al., 2010 } & \text {. }\end{array}$

$180 \times 238 \mathrm{~mm}(300 \times 300 \mathrm{DPI})$ 